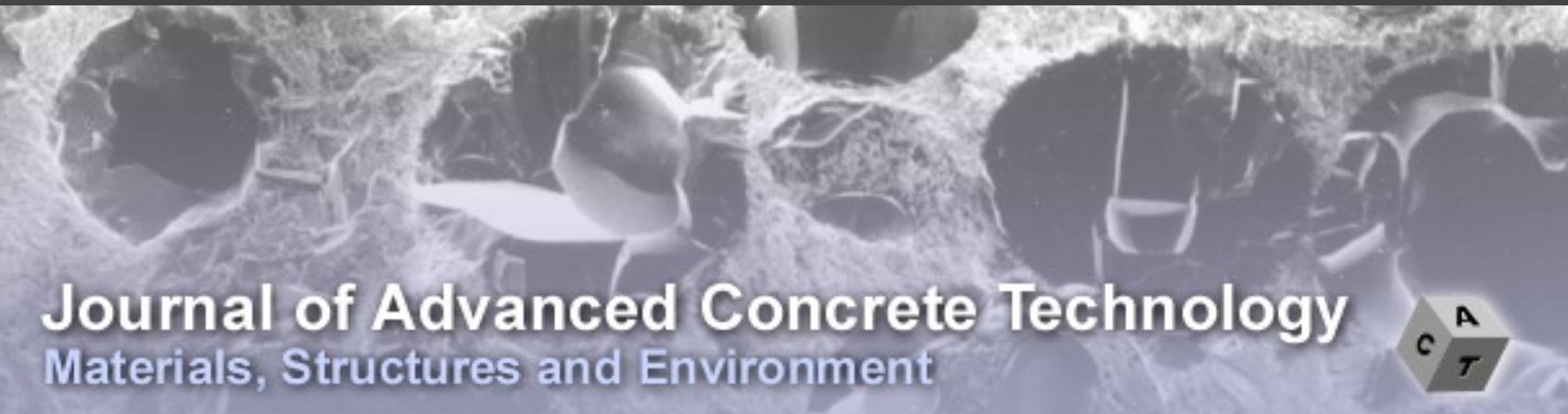

\title{
Effect of Self-Healing on the Different Transport Properties of Cementitious Composites
}

Ahmed Alyousif, Mohamed Lachemi, Gurkan Yildirim, Mustafa Şahmaran

Journal of Advanced Concrete Technology, volume 13 (2015 ), pp. 112-123

\section{Related Papers Click to Download full PDF!}

Self-healing capability of fiber reinforced cementitious composites

Daisuke Homma, Hirozo Mihashi, Tomoya Nishiwaki

Journal of Advanced Concrete Technology, volume 7 (2009), pp. 217-228

Experimental Study on Self-Healing Capability of FRCC Using Different Types of Synthetic Fibers

Tomoya Nishiwaki, Marina Koda, Hirozo Mihashi, Takatsune Kikuta

Journal of Advanced Concrete Technology, volume 10 (2012), pp. 195-206

Recovery of Protective Performance of Cracked Ultra High Performance Strain Hardening Cementitious Composites (UHP-SHCC) due to Autogenous Healing

Minoru Kunieda, Choonghyun Kang, Naoshi Ueda, Hikaru Nakamura

Journal of Advanced Concrete Technology, volume 10 (2012), pp. 313-322

\section{Click to Submit your Papers}




\title{
Effect of Self-Healing on the Different Transport Properties of Cementitious Composites
}

\author{
Ahmed Alyousif ${ }^{1}$, Mohamed Lachemi ${ }^{2}$, Gurkan Yildirim ${ }^{3}$ and Mustafa Şahmaran*4
}

\begin{abstract}
This research focuses on the effects of self-healing on the different transport properties of microcracked Engineered Cementitious Composites (ECC) with different maturity levels and incorporating three different mineral admixtures with greatly varying chemical compositions. The effect of self-healing capability on transport properties was assessed using water sorptivity and rapid chloride permeability tests (RCPT). Experimental results revealed that with the selection of proper mineral admixture type and conditioning, a 92\% recovery in water sorptivity results is attainable. Moreover, a considerable amount of this recovery took place after only 7 days of water curing, significantly lowering the risk of water transport by capillary suction into cracked ECC. Like the sorptivity measurements, most of the chloride ion penetrability values could also be reduced up to a great extent after 30 days of water curing, so most of the results fell into the low penetrability level during this period, as prescribed by ASTM C1202. Although self-healing in terms of RCPT results started to be visible in the first 7 days of water curing, significant improvements needed more time in RCPTs, unlike the sorptivity results. Overall, these findings suggest that the rate of self-healing varies depending on the different transport mechanisms dominant in a given infrastructure type during its service life.
\end{abstract}

\section{Introduction}

It is a well-established fact that the performance of concrete mixtures is not solely limited to mechanical property characterization but is also significantly affected by the parameters affecting durability of the material. Durability has tremendous effects on the economy and serviceability of concrete, reinforced concrete and pre-stressed concrete structures, making it a key issue. However, civil infrastructures are often under the influence of environmental impacts and/or mechanical loads that result in drastic changes in durability through cracking. Once crack occurrence takes place, restoring the sound (untouched) properties of concrete is not an easy task since cracks introduce additional pathways which accelerate the transportation of various media (e.g. liquids, aggressive ions, gaseous substances) into the material. As the transport of those various agents continues, contingency for disruptive mechanisms such as corrosion, sulfate and acid attack, and freeze/thaw susceptibility significantly increases, making the concrete highly vulnerable to fast and serious deterioration.

${ }^{1} \mathrm{PhD}$ Candidate, Department of Civil Engineering, Ryerson University, Toronto, ON, Canada.

${ }^{2}$ Professor, Department of Civil Engineering, Ryerson University, Toronto, ON, Canada.

${ }^{3} \mathrm{PhD}$ Candidate, Department of Civil Engineering, Gazi University, Ankara, Turkey.

${ }^{4}$ Professor, Department of Civil Engineering, Gazi University, Ankara, Turkey.

*Corresponding author,

E-mail: sahmaran@gazi.edu.tr
In many instances, crack-originated and further exacerbated deterioration necessitates urgent renovation of the damaged areas. However, repair and/or maintenance applications can be troublesome and the costs involved in renewing deteriorated concrete structures can be high; in extreme cases, even higher than the initial construction cost. In addition to the financial issues, the environmental impacts of the restoration of damaged infrastructures can prevent the performance of repair and/or maintenance applications (Witmann 1998). In this regard, the intrinsic self-healing ability of cracks in concrete material - further favored by the formation of cracks with smaller widths - is an attractive methodology for durability and in some cases for mechanical property regain.

Concrete is brittle and the brittleness of the material becomes more pronounced in higher-strength grades. This phenomenon has been of interest to many researchers; studies using fibers to address the high brittleness of concrete started very early on (Romualdi and Mandel 1964). Invaluable efforts to modify the brittleness of conventional concrete materials made way for the emergence of new class of materials known as High Performance Fiber Reinforced Cementitious Composites (HPFRCC) (Naaman and Reinhardt 2003). Engineered Cementitious Composites (ECCs), a special kind of HPFRCC, were first introduced about 20 years ago (Li 1998). The main characteristic of ECCs, differentiating it from conventional fiber reinforced concretes (FRCs), is their high tensile strain capacity and strainhardening behavior under uniaxial tensile loading, which is supplied through a delicate balance among the individual components of the cementitious system (i.e. fibers, matrix and fiber-to-matrix interface) resulting 
from the micromechanics-based material design (Li 2001). Superior ductility, which is a direct result of high tensile strain capacity and strain-hardening behavior, is realized by the formation of many closely-spaced multiple microcracks (widths of less than $100 \mu \mathrm{m}$ ), making ECCs at least 100 times higher in ductility than conventional concrete used for common construction practices (Li 2003). Taking into account the formation of wellcontrolled micron-sized cracks in ECCs, they can be regarded as promising materials for enhanced selfhealing capability, since tolerable crack widths are reported to be one of the decisive parameters influencing the mechanism (Edvardsen 1999).

Over the last decade, self-healing phenomena have gained increasing popularity in the research community. Although different self-healing methodologies have been applied to functionalize the mechanism, much of the attention has been paid to the self-repair of damage (i.e. cracks) with no external intervention ( $\mathrm{Li}$ and Herbert 2012). The ability of concrete material to self-heal its own cracks is mainly associated with the formation of calcite and further C-S-H gels when no additional healing agents are used. Despite the effectiveness of both mechanisms in terms of crack plugging performance, changes in transport properties are more closely related to the formation of calcite, which is important for infrastructures that will be in contact with water or moisture during their service lives. The influence of self-healing on several transport properties of ECC has already been the topic of several studies. Lepech and $\mathrm{Li}$ (2009) studied the self-healing of microcracks in standard ECC mixtures where the extent was evaluated by changes in water permeability. According to this study, it was concluded that permeability of ECCs stabilized as a consequence of self-healing, and that damaged ECC specimens have similar water permeability coefficients as sound ones, provided that crack widths are kept under the threshold of $100 \mu \mathrm{m}$. Sahmaran et al. (2014) also reported substantial amounts of self-healing attainment in terms of chloride ion penetrability when pre-cracked ECC specimens were allowed to self-heal their own damage. As one of the governing transport mechanisms, the diffusion of chloride ions in standard ECC (M45) mixtures ponded in $\mathrm{NaCl}$ solution was investigated by Sahmaran et al. (2007), who concluded that 30 days of exposure to salt solution led the microcracks in ECC to self-heal markedly, resulting in relatively low diffusion coefficients. Although all of the abovementioned studies are of great value and supply important information, permeability and diffusion may not be the governing mechanisms contributing to the transport of various media in cracked concrete, especially in cases where infrastructures are exposed to the drying actions of sun and wind. Under such conditions (dry and/or partially dry state), a dominant transport mechanism is more likely to be due to the capillary suction forces existing in the evacuated capillary cavities present in the matrix
(Martys and Ferraris 1997). When concrete material itself has a high capillarity, water and aggressive agents can more easily penetrate the material, accelerating rebar corrosion. Therefore, in order to better simulate actual field conditions and see how capillary suction is changed with the effect of self-healing, an experimental study was undertaken. The study concentrated mainly on the sorptivity measurements of pre-cracked and sound ECC specimens before and after exposure to environmental conditioning for crack healing. To observe the extent and rate of self-healing on another transport mechanism, additional rapid chloride permeability tests (RCPTs) were performed. Moreover, during the production of ECCs, mineral admixtures (MAs) with different chemical compositions (which can be decisive on self-healing capability of the mixtures) were used.

\section{Experimental program}

\subsection{Materials, mixture proportions and basic mechanical properties}

Ordinary Portland cement (PC), silica sand with maximum aggregate size (MAS) of $400 \mu \mathrm{m}$ and water absorption capacity of $0.3 \%$, water, poly-vinyl alcohol (PVA) fibers with a diameter of $39 \mu \mathrm{m}$, nominal tensile strength of $1610 \mathrm{MPa}$ and specific gravity of 1.3, and high range water reducing admixture (HRWRA) were used for the production of the ECC mixtures. In addition, different mineral admixtures (MA) representing greatly varying chemical compositions were incorporated into the mixtures. One type of ground granulated blast furnace slag (S, [ECC_S]) along with two different fly ashes (FA) were selected as different MAs. The fly ashes were low lime fly ash ([FA-L], ECC_L) and high lime fly ash ([FA-H], ECC_L). The chemical and physical properties of the Portland cement and mineral admixtures are presented in Table 1, along with the particle size distributions of solid ingredients in Fig. 1. The ECC mixtures were produced with a water to cementitious materials $(\mathrm{PC}+\mathrm{MA})$ ratio $(\mathrm{W} / \mathrm{CM})$ of 0.27 and a mineral admixture (i.e. FA or $\mathrm{S}$ ) to Portland cement ratio (MA/PC) of 1.2, by mass. Mixture proportion details are shown in Table 2.

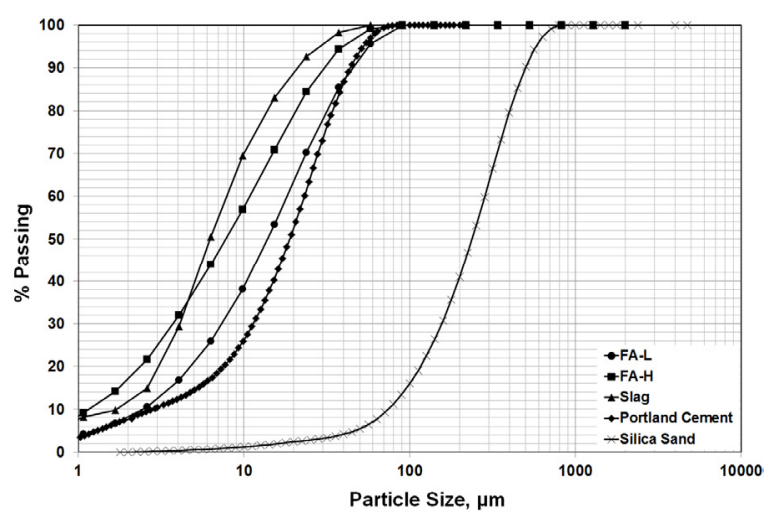

Fig. 1 Particle size distributions of silica sand, Portland cement and different mineral admixtures. 
Table 1 Chemical and physical properties of PC and different MA types.

\begin{tabular}{|l|c|c|c|c|}
\hline Chemical Composition, \% & PC & FA-L & FA-H & S \\
\hline $\mathrm{SiO}_{2}$ & 20.8 & 57.0 & 41.8 & 35.1 \\
\hline $\mathrm{Al}_{2} \mathrm{O}_{3}$ & 5.6 & 21.0 & 18.8 & 10.4 \\
\hline $\mathrm{Fe}_{2} \mathrm{O}_{3}$ & 3.4 & 4.2 & 6.4 & 0.79 \\
\hline $\mathrm{MgO}$ & 2.5 & 1.8 & 4.7 & 12.2 \\
\hline $\mathrm{CaO}$ & 61.4 & 9.8 & 21.8 & 38.3 \\
\hline $\mathrm{Na}_{2} \mathrm{O}$ & 0.19 & 2.2 & 1.7 & 0.12 \\
\hline $\mathrm{K}_{2} \mathrm{O}$ & 0.77 & 1.5 & 0.63 & 0.37 \\
\hline $\mathrm{Loss}_{\text {on Ignition }}$ & 2.2 & 1.3 & 0.68 & 1.1 \\
\hline $\mathrm{SiO}_{2}+\mathrm{Al}_{2} \mathrm{O}_{3}+\mathrm{Fe}_{2} \mathrm{O}_{3}$ & 29.8 & 82.2 & 67.0 & 46.3 \\
\hline Physical Properties $_{\text {Specific Gravity }}$ & & & \\
\hline Blaine Fineness $\left(m^{2} / \mathrm{kg}\right)$ & 3.06 & 2.02 & 2.61 & 2.87 \\
\hline
\end{tabular}

Table 2 Mixture proportions and basic mechanical properties of ECC mixtures.

\begin{tabular}{|l|c|c|c|}
\hline \multirow{2}{*}{ Mixture Proportions } & \multicolumn{3}{|c|}{ Mix ID. } \\
\cline { 2 - 4 } & ECC_L & ECC_H & ECC_S \\
\hline Cement & 1.0 & 1.0 & 1.0 \\
\hline Sand & 0.80 & 0.80 & 0.80 \\
\hline FA/PC & 1.2 & 1.2 & - \\
\hline S/PC & - & - & 1.2 \\
\hline W/CM & 0.27 & 0.27 & 0.27 \\
\hline PVA, $\left(\mathrm{kg} / \mathrm{m}^{3}\right)$ & 26 & 26 & 26 \\
\hline HRWRA $\left(\mathrm{kg} / \mathrm{m}^{3}\right)$ & 3.9 & 4.6 & 5.3 \\
\hline Mechanical Properties $(28$ days) & & & \\
\hline Compressive strength $(\mathrm{MPa})$ & 55.5 & 58.7 & 77.2 \\
\hline Flexural strength $(\mathrm{MPa})$ & 10.2 & 11.6 & 11.5 \\
\hline Flexural deformation $(\mathrm{mm})$ & 4.3 & 2.7 & 2.0 \\
\hline
\end{tabular}

Basic mechanical property characterizations of the ECC mixtures were made using $50 \mathrm{~mm}$ cubic specimens for compressive strength and $360 \times 75 \times 50 \mathrm{~mm}$ prism (length $\times$ depth $\times$ width) specimens for flexural parameters. After 24 hours inside the molds at $23 \pm 2{ }^{\circ} \mathrm{C}, 50 \pm 5 \% \mathrm{RH}$, all of the specimens were moved into plastic bags to be cured at $23 \pm 2{ }^{\circ} \mathrm{C}, 95 \pm 5 \% \mathrm{RH}$ for 7 days. Beyond the initial 7-day curing, specimens were kept in a laboratory environment at $23 \pm 2{ }^{\circ} \mathrm{C}, 50 \pm 5 \% \mathrm{RH}$ for an additional 21 days. Table 2 shows the basic mechanical properties (i.e. compressive strength and flexural parameters [flexural strength and flexural deformation]) of ECC specimens, acquired by averaging at least six specimens. One can easily see that average 28-day compressive strength results of the ECC_S mixture $(77.2 \mathrm{MPa})$ were the highest, which was attributed to the high cementing capability and increased specific surface area of slag particles. The lowest average compressive strength result was obtained from the ECC_L mixture with 55.5 $\mathrm{MPa}$. This finding was related to the higher pozzolanic capacity of low lime fly ash particles, whose effectiveness is anticipated at later ages. Average flexural strength results of the ECC mixtures varied between 10.2 and $11.6 \mathrm{MPa}$. One point worth noting is that the differences in flexural strength results were not as high as those in the compressive strength results. This behavior is related to the more elaborate material properties such as tensile first cracking strength, ultimate tensile strength and tensile strain capacity, that govern flexural strength results (Qian et al. 2009). Flexural deformation values, which are a reflection of the ductility of ECC materials, are also shown in Table 2. As seen in the table, among all the different mixture types, the ECC S mixture showed the lowest average flexural deformation at the end of 28 days $(2.0 \mathrm{~mm})$, while the ECC_L mixture was more than two times that of the ECC_ $\bar{S}$ specimens with $4.3 \mathrm{~mm}$ mid-span beam deformation level. Increased ductility of the ECC_L specimens was attributed to the tendency of low lime fly ash particles to reduce PVA fiber/matrix interface chemical bond and matrix toughness, while increasing the interface frictional bond in favor of attaining high tensile strain capacity (Wang and Li 2007).

\subsection{Sample preparation, pre-cracking and methods for self-healing evaluation}

As previously mentioned, this paper concentrates on the sorptivity measurements of sound and pre-cracked ECC specimens to evaluate self-healing performance. Rapid chloride permeability tests (RCPTs) and the assessment of crack characteristics were also performed. $360 \times 75 \times 50 \mathrm{~mm}$ prism (length $\times$ depth $\times$ width) specimens with different ECC mixtures were produced for sorptivity measurement. After 24 hours inside the molds at $23 \pm 2{ }^{\circ} \mathrm{C}$ and $50 \pm 5 \% \mathrm{RH}$, specimens were removed from the molds and placed in impermeable plastic bags at $23 \pm 2{ }^{\circ} \mathrm{C}$ and $95 \pm 5 \% \mathrm{RH}$ cured for 7,28 and 90 days. Before the tests, three separate specimens from each mixture and testing age were loaded up to failure under four-point bending loading for the determination of ultimate bending deformation capacities. The results were in the range of 1.7 to $4.8 \mathrm{~mm}$, depending on the usage of different mineral admixtures and initial curing age. Therefore, $80 \%$ of the ultimate bending deformation capacity of ECCs was set as a pre-cracking limit for all specimens. After each maturity level (7, 28 and 90 days) was reached, specimens were pre-loaded up to $80 \%$ of their four-point bending deformation capacity to obtain cracks with different characteristics. After the introduction of pre-loading, prisms measuring $75 \times 75 \times 50 \mathrm{~mm}$ were cut from the central portions of each specimen to evaluate sorptivity properties (Fig. 2). Sorptivity tests were performed using four different prisms for each age, following the procedures of ASTM

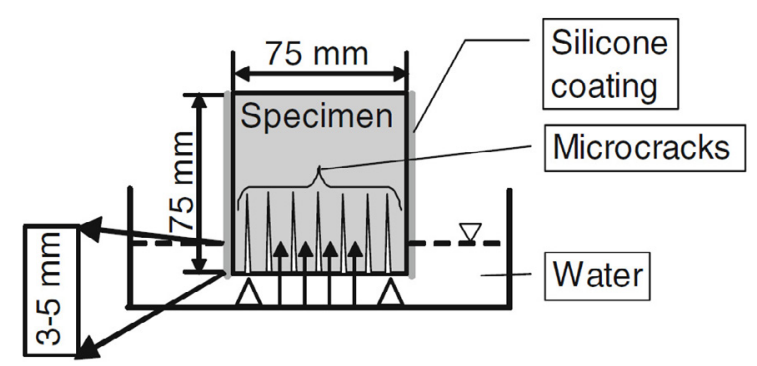

Fig. 2 Schematic representation of sorptivity test setup and cut-off prism specimen. 
C 1585. For comparison, two out of the four prisms were kept sound (uncracked) and the rest were preloaded as described above. Special attention was paid to the introduction of cracks with varying numbers and widths during pre-loading. For the evaluation of selfhealing through sorptivity measurements, 7, 28 and 90day old sound and pre-loaded specimens were individually subjected to continuous water (CW) curing at $23 \pm 2{ }^{\circ} \mathrm{C}$ for an additional $7,30,60$ and 90 days, and the tests were repeated after the completion of additional curing periods. Before the commencement of sorptivity testing, specimens were left to dry in an oven at $50 \pm 5{ }^{\circ} \mathrm{C}$ until a constant weight was obtained. After all specimens were completely dry, they were immersed in water by 3-5 mm, as seen in Fig. 2. To ensure onedirectional flow through the specimens and reduce the chance of water evaporation, prisms were laterally sealed with silicon coating. Changes in mass of the ECC prism specimens that were left to absorb water through capillary action were recorded at time intervals of $1,2,3$, $4,6,8,12,16,20,25,36,49,64,81,120$ and $360 \mathrm{~min}-$ utes. The rate of absorption ( $\mathrm{mm}$ ), defined as the change in mass ( $\mathrm{g}$ ) divided by the cross sectional area of the test specimen $\left(\mathrm{mm}^{2}\right)$ and the density of water at the recorded temperature $\left(\mathrm{g} / \mathrm{mm}^{3}\right)$, was plotted against square root of time $\left(\min ^{1 / 2}\right)$. The slopes of the obtained lines were regarded as the sorptivity index $\left(\mathrm{S}_{\mathrm{o}}\right)$ of ECCs during the six hours of initial testing. For all specimens, this slope was obtained by using least-squares, linear regression analysis of the plot of absorption rate versus square root of time. Additionally, changes in the widths of cracks formed over the specimens used for sorptivity tests were observed with a video microscope at the end of each pre-determined testing age.

As another way of detecting self-healing performance, rapid chloride permeability tests (RCPTs) were performed in accordance with ASTM C 1202. After one day of curing in laboratory conditions at $23 \pm 2{ }^{\circ} \mathrm{C}$ and $50 \pm 5 \% \mathrm{RH}, \varnothing 100 \times 200 \mathrm{~mm}$ cylindrical specimens were removed from the molds and then kept in plastic bags at $23 \pm 2{ }^{\circ} \mathrm{C}$ and $95 \pm 5 \% \mathrm{RH}$ until the end of 7,28 and 90 days. After the initial aging, $\varnothing 100 \times 200 \mathrm{~mm}$ cylinders were cut into $\varnothing 100 \times 50 \mathrm{~mm}$ pieces using a diamond blade saw. Before the pre-loading of specimens, the same procedures as those used for the prisms were followed to define the ultimate splitting tensile deformation capacities of different mixtures under splitting tensile loading. Results varied between $1.3 \mathrm{~mm}$ and 1.9 $\mathrm{mm}$, depending on different MAs and initial curing periods. Then, in order to create microcracks, $\varnothing 100 \times 50$ $\mathrm{mm}$ ECCs were pre-loaded up to $80 \%$ of their splitting tensile deformation capacities at the ages of 7, 28 and 90 days under splitting tensile loading at a loading rate of $0.005 \mathrm{~mm} / \mathrm{s}$. Six cylinders from each mixture, three of which were sound and three pre-loaded, were used for the RCPTs. Just as in the sorptivity measurements, tests were repeated after 7, 30, 60 and 90 days of CW exposure beyond initial curing periods to observe self- healing performance of ECCs. Although different crack characteristics were acquired with the application of pre-loading to ECCs with different mineral admixtures (MAs), the effect of self-healing on crack recoveries has not been accounted for in this study since this point has already been investigated in detail in several previous papers (Sahmaran et al. 2013, 2014).

\section{Results and discussion}

\subsection{Sorptivity test \\ 3.1.1 Unhealed specimens}

Table 3 shows the crack characteristics and sorptivity index values of 7-, 28- and 90-day-old ECC specimens that were not subjected to further $\mathrm{CW}$ curing for selfhealing assessment. As seen from the table, the type of mineral admixture and initial curing age (maturity level) are influential on sorptivity results. Considering the effects of initial curing on the results of sound specimens, it can clearly be stated that there were remarkable decrements in the values when curing ages were prolonged from 7 to 90 days. For example, the average 7day sorptivity index of the ECC_L specimens was $0.0787 \mathrm{~mm} / \mathrm{min}^{1 / 2}$, while the same value decreased by $61 \%$ and $87 \%$ to 0.0317 and $0.0099 \mathrm{~mm} / \mathrm{min}^{1 / 2}$ levels for the 28 and 90-day-old specimens, respectively. Although the differences in results varied greatly depending on the mineral admixture type, the general trend was irrespective of MA type and valid for all of the mixtures. The observed behavior of sound ECC specimens upon exposure to longer curing periods was an anticipated outcome due to continuing hydration reactions and pozzolanic capacity, both of which are the main mechanisms contributing to the attainment of dense microstructure and disconnected pores.

Another notable point related to the sorptivity results of sound ECC mixtures is that ECC_S specimens at all maturity levels displayed the lowest sorptivity results, with values reaching $0.0115,0.0049$ and 0.0043 $\mathrm{mm} / \mathrm{min}^{1 / 2}$ levels at the end of 7, 28 and 90 days, respectively. It appears that slag particles, due to their significantly higher specific surface area $\left(430 \mathrm{~m}^{2} / \mathrm{kg}\right)$, contributed well to the advancements in hydration and pozzolanic reactions compared to fly ash. The higher fineness of slag particles is also of great importance due to so-called "filler effect," which can make major contributions to better distribution of particles in cementitious systems and denser microstructures. In the case of sorptivity results of ECC mixtures incorporating fly ash, there is a clear difference in the values at and after 7 days of initial curing based on the type of fly ash. As seen from Table 3, the 7-day average sorptivity index of ECC_H specimens was less than $50 \%$ of that of the $\mathrm{ECC}_{-}^{-} \mathrm{L}$, although the same finding was the opposite after 90 days of initial curing; the average sorptivity index of 90-day-old ECC_L specimens (0.0099 $\mathrm{mm} / \mathrm{min}^{1 / 2}$ ) was $27 \%$ less than that of ECC H specimens $\left(0.0135 \mathrm{~mm} / \mathrm{min}^{1 / 2}\right)$. The lower sorptivity values 
Table 3 Crack characteristics and sorptivity indexes of ECC specimens.

\begin{tabular}{|c|c|c|c|c|c|c|c|c|c|}
\hline $\begin{array}{l}\text { Initial Curing } \\
\text { Period }\end{array}$ & Mix ID. & $\begin{array}{c}\# \text { of } \\
\text { Cracks }\end{array}$ & $\begin{array}{l}\text { Average Crack } \\
\text { Width }(\mu \mathrm{m})\end{array}$ & $\begin{array}{c}\text { \# of } \\
\text { Specimens }\end{array}$ & \multicolumn{5}{|c|}{ Sorptivity $\left(\mathrm{mm} / \min ^{1 / 2}\right)$} \\
\hline \multirow{16}{*}{7 Days } & \multirow{6}{*}{ ECC_L } & & & & 7 & $7+7$ & $7+30$ & $7+60$ & $7+90$ \\
\hline & & 0 & - & 2 & 0.0787 & 0.0400 & 0.0275 & 0.0113 & 0.0089 \\
\hline & & 2 & 75 & 1 & 0.0927 & 0.0465 & 0.0297 & 0.0187 & 0.0103 \\
\hline & & 3 & 75 & 1 & $0.1052^{*}$ & - & - & - & - \\
\hline & & 5 & 70 & 1 & $0.1285^{*}$ & - & - & - & - \\
\hline & & 6 & 65 & 1 & 0.1482 & 0.0610 & 0.0361 & 0.0201 & 0.0122 \\
\hline & \multirow{10}{*}{ ECC_S } & 0 & - & 2 & 0.0311 & 0.0280 & 0.0220 & 0.0145 & 0.0105 \\
\hline & & 3 & 50 & 1 & 0.0550 & 0.0390 & 0.0301 & 0.0271 & 0.0199 \\
\hline & & 4 & 65 & 1 & $0.0558^{*}$ & - & - & - & - \\
\hline & & 5 & 80 & 1 & $0.0678^{*}$ & - & - & - & - \\
\hline & & 6 & 75 & 1 & 0.0749 & 0.0590 & 0.0472 & 0.0398 & 0.0305 \\
\hline & & 0 & - & 2 & 0.0115 & 0.0061 & 0.0044 & 0.0040 & 0.0037 \\
\hline & & 2 & 100 & 1 & 0.0241 & 0.0097 & 0.0076 & 0.0063 & 0.0054 \\
\hline & & 3 & 85 & 1 & $0.0303^{*}$ & - & - & - & - \\
\hline & & 4 & 70 & 1 & $0.0391^{*}$ & - & - & - & - \\
\hline & & 6 & 75 & 1 & 0.0593 & 0.0192 & 0.0122 & 0.0097 & 0.0088 \\
\hline \multirow{16}{*}{28 Days } & \multirow{6}{*}{ ECC_L } & & & & 28 & $28+7$ & $28+30$ & $28+60$ & $28+90$ \\
\hline & & 0 & - & 2 & 0.0317 & 0.0290 & 0.0117 & 0.0097 & 0.0082 \\
\hline & & 2 & 65 & 1 & 0.0495 & 0.0320 & 0.0216 & 0.0129 & 0.0106 \\
\hline & & 3 & 50 & 1 & $0.0591^{*}$ & - & - & - & - \\
\hline & & 5 & 65 & 1 & $0.0723^{*}$ & - & - & - & - \\
\hline & & 6 & 65 & 1 & 0.0860 & 0.0490 & 0.0278 & 0.0167 & 0.0120 \\
\hline & & 0 & - & 2 & 0.0249 & 0.0235 & 0.0154 & 0.0129 & 0.0097 \\
\hline & & 3 & 80 & 1 & 0.0328 & 0.0311 & 0.0304 & 0.0230 & 0.0173 \\
\hline & ECC_H & 4 & 75 & 1 & $0.0407^{*}$ & - & - & - & - \\
\hline & & 5 & 85 & 1 & $0.0422^{*}$ & - & - & - & - \\
\hline & & 6 & 60 & 1 & 0.0596 & 0.0403 & 0.0351 & 0.0291 & 0.0298 \\
\hline & & 0 & - & 2 & 0.0049 & 0.0043 & 0.0041 & 0.0039 & 0.0037 \\
\hline & & 2 & 85 & 1 & 0.0082 & 0.0074 & 0.0070 & 0.0065 & 0.0051 \\
\hline & ECC_S & 3 & 50 & 1 & $0.0157^{*}$ & - & - & - & - \\
\hline & & 4 & 75 & 1 & $0.0265^{*}$ & - & - & - & - \\
\hline & & 6 & 65 & 1 & 0.0376 & 0.0354 & 0.0351 & 0.0349 & 0.0261 \\
\hline & & & & & 90 & $90+7$ & $90+30$ & $90+60$ & $90+90$ \\
\hline & & 0 & - & 2 & 0.0099 & 0.0088 & 0.0081 & 0.0082 & 0.0084 \\
\hline & ECC_L & 2 & 80 & 1 & 0.0145 & 0.0118 & 0.0110 & 0.0102 & 0.0105 \\
\hline & & 3 & 75 & 1 & $0.0253^{*}$ & - & - & - & - \\
\hline & & 4 & 65 & 1 & $0.0364^{*}$ & - & - & - & - \\
\hline & & 5 & 60 & 1 & 0.0460 & 0.0389 & 0.0355 & 0.0282 & 0.0240 \\
\hline & & 0 & - & 2 & 0.0135 & 0.0121 & 0.0106 & 0.0103 & 0.0092 \\
\hline & & 2 & 70 & 1 & 0.0276 & 0.0231 & 0.0225 & 0.0211 & 0.0193 \\
\hline 90 Days & ECC_H & 2 & 60 & 1 & $0.0341^{*}$ & - & - & - & - \\
\hline & & 4 & 95 & 1 & $0.0441^{*}$ & - & - & - & - \\
\hline & & 5 & 55 & 1 & 0.0484 & 0.0412 & 0.0393 & 0.0329 & 0.0322 \\
\hline & & 0 & - & 2 & 0.0043 & 0.0038 & 0.0036 & 0.0030 & 0.0029 \\
\hline & & 3 & 65 & 1 & 0.0095 & 0.0086 & 0.0083 & 0.0077 & 0.0083 \\
\hline & ECC_S & 4 & 75 & 1 & $0.0156^{*}$ & - & - & - & - \\
\hline & & 5 & 75 & 1 & $0.0250^{*}$ & - & - & - & - \\
\hline & & 8 & 85 & 1 & 0.0486 & 0.0435 & 0.0410 & 0.0361 & 0.0342 \\
\hline
\end{tabular}

*: Self-healing performance for these specimens was not measured.

of the ECC $\mathrm{H}$ specimens after limited curing time is believed to be due to the dual effectiveness of high lime fly ash particles on both pozzolanicity and cementing behavior, which reduced the sorptivity, especially during early ages. However, the superior pozzolanic capacity of low lime fly ash appeared to take over the sorptivity results at later ages so that percentual changes between 7 and 90 days were $87 \%$ and $57 \%$, taking into account the ECC_L and ECC_H mixtures, respectively.
Upon subjection to pre-loading, there were exponential increments in sorptivity results of ECC mixtures (Fig. 3) without any regard to the type of MAs and initial curing period. This was an anticipated outcome since microcracks are likely to introduce additional pathways where water can be sucked into the material itself through capillary action. Increases in the number of cracks resulted in escalated sorptivity results as well. Taking the 7-day-old ECC_S mixtures as an example, 

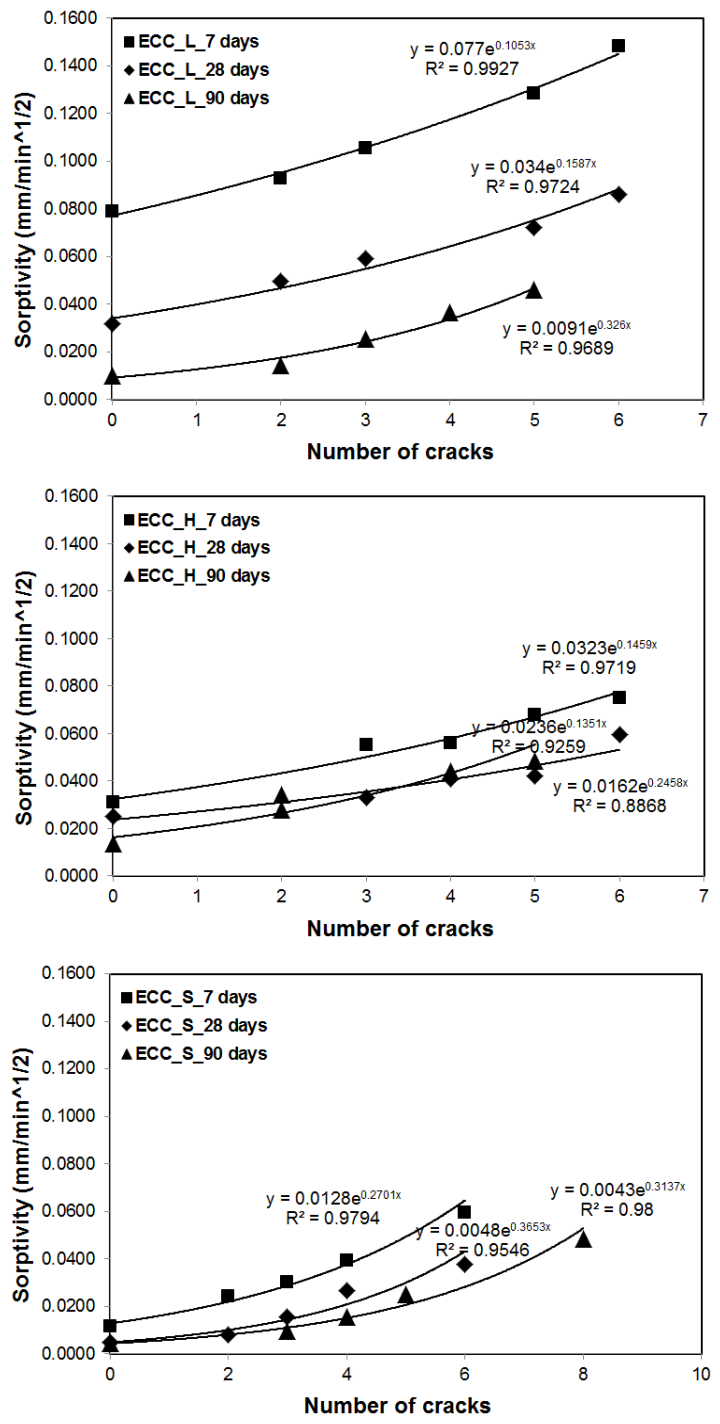

Fig. 3 Changes in sorptivity indexes of ECC mixtures with the increase in number of cracks.

the sorptivity results of specimens with two cracks were $0.0241 \mathrm{~mm} / \mathrm{min}^{1 / 2}$, although the same result was 0.0593 $\mathrm{mm} / \mathrm{min}^{1 / 2}$ in the case of specimens with six cracks. Moreover, this trend was valid for all of the mixtures and initial curing ages used in this study, showing that in highly damaged ECCs, capillary pores and microcracks tend to become saturated in a very limited time (Sahmaran and Li 2009). When the combined influence of crack formation and initial curing periods on sorptivity values of ECCs is considered, it appears that cracking has a more profound effect on escalating the results of ECC specimens cured for a longer time. For example, when a comparison is made between 7- and 90-day-old ECC_L specimens with no cracks and the maximum number of cracks, sorptivity results of the 90-day-old pre-loaded specimens (365\% compared to sound specimens) increased more than those of the 7-day-old specimens (88\% compared to sound specimens) (Table 3). This modality held true for the rest of the mixtures, although crack characteristics altered significantly. The reason for the significant differences in the sorptivity results of sound and pre-loaded specimens cured for short and long periods could be related to the effect of different initial curing periods on the interconnection of capillary pores. For the specimens cured for shorter durations, there was less possibility of capillary pores being disconnected efficiently due to inadequate curing. Therefore, these disconnected pores were expected to have a stronger influence on water sorptivity, making the effect of microcracking on the results less visible for specimens of lower maturity. On the other hand, for specimens of higher maturity, disconnection of the capillary pores was more likely to occur, bringing mechanically-introduced microcracks into the more visible. However, it should be kept in mind that crack length and the tortuosity of the crack path are as important as crack width and could be responsible for the variations in overall sorptivity results. It is of great importance to note that although 7-day-old specimens seem to exhibit relatively higher increments in sorptivity with the increased number of cracks compared to 90-day-old specimens, percent changes were calculated in accordance with the significantly lower sorptivity results of sound specimens at 90 days of age which led the amount of percent increment look smaller for this mixture.

Taking into consideration the effect of pre-loading on the sorptivity results of different mixtures, it is noticeable that pre-loading was much more efficient in the case of ECC_S specimens compared to ECC mixtures incorporating fly ash, especially at later ages. For example, while a $141 \%$ difference was found between the results of 7-day-old ECC_H specimens with no cracks (sound) and the specimens with the maximum number of cracks, the difference rose to $416 \%$ for the ECC_S mixture. This is believed to be due to the effect of different mineral admixtures on the maturity of specimens and a possible explanation regarding this point has already been made in the previous paragraph. Despite the substantial increments in the sorptivity values of ECC_S specimens with applied pre-loading, it should not be overlooked that final sorptivity results were lower than in the other mixtures after almost all ages and crack formations, which is related to the tightness of ECC_S matrices against water movement.

\subsubsection{Effects of self-healing}

Table 3 shows sorptivity measurements taken after the application of further 7, 30, 60 and 90 days of CW curing for the evaluation of self-healing in ECCs with the minimum number of cracks (2 to 3 ) and the maximum number of cracks (5 to 8), along with the sound ones (no cracks). In order to better show the self-healing performance, percentual reductions in the results are presented in Fig. 4. As can be concluded from both Table 3 and Fig. 4, CW curing was quite influential on improving the sorptivity results, regardless of the type of min- 

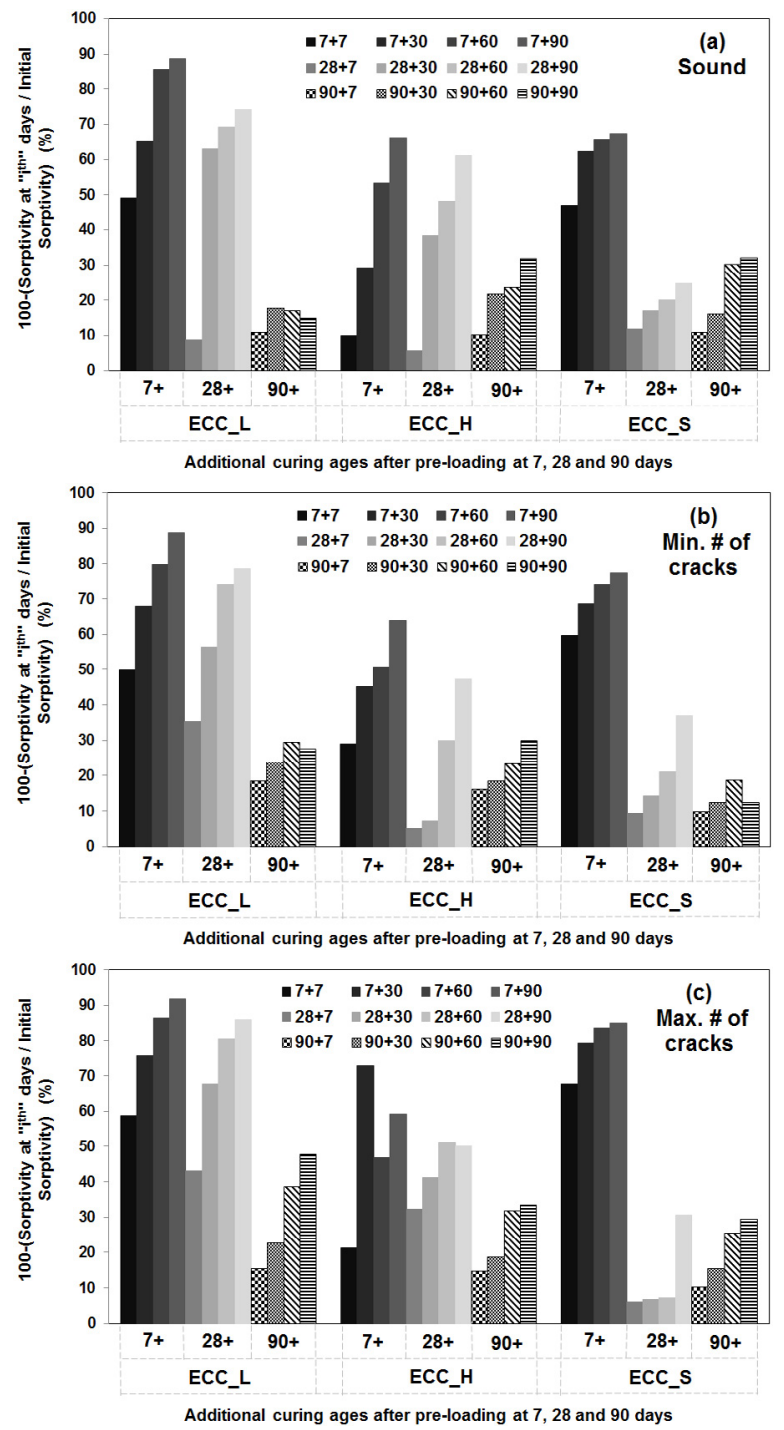

Fig. 4 Effect of self-healing on sorptivity results of ECCs with a) no cracks b) min. \# of cracks c) max. \# of cracks.

eral admixture and number of cracks. Generally speaking, there were sharp decreases in the sorptivity of ECC specimens after 7 days of initial CW curing was applied to the specimens, although the dependency of improvements on different mineral admixture types and crack characteristics was quite clear. Faster reductions of results with the application of a limited duration of $\mathrm{CW}$ curing were most probably due to the larger availability of unhydrated particles ready to react further in the systems. Moreover, the higher number of capillary pores of younger specimens is more likely to be saturated faster and contribute to self-healing more efficiently.

The effect of different initial curing ages on the reductions in sorptivity results was profound. For example, the 7-day-old ECC_L specimens with the maximum number of cracks displayed a healing rate of $76 \%$ after 30 days of $\mathrm{CW}$ curing, while for the same specimens of 90-day age, healing after the same amount of time was limited to $23 \%$. This finding was also true for the rest of the ECCs, despite the fact that there were changes in crack numbers and widths. The finding was correlated with the gradual exhaustion of anhydrous materials in the composites cured for a longer time, which reduced the possibility for self-healing to occur. Additionally, this result was more pronounced in the sound specimens than in the load-induced ones (Fig. 4), which could be due to the fact that water ingress through microcracks was easier and contributed well to carbonation, which is believed to be as powerful as hydration reaction (Edvardsen 1999). Accordingly, water movement into solid specimens is expected to be limited due to the significantly dense matrices of ECCs, which can restrict reductions in sorptivity results. Given the small size $(75 \times 75 \times 50 \mathrm{~mm})$ of the tested specimens, however, it is likely that water moved more easily than expected and contributed to self-healing in solid specimens as well. Despite the reduced self-healing rates with prolonged curing ages, it is important to note that self-healing at later ages was still at levels that cannot be overlooked, which provides invaluable information about the lifetime of the mechanism.

The influence of different mineral admixtures on the sorptivity results of additionally-cured specimens is another point requiring further discussion. As seen from Fig. 4, the ECCs with low lime fly ash particles (ECC_L) showed superior self-healing performance, particularly when they were initially cured for a limited time, such as 7 days. Considering the reductions in the results of the sound specimens, sorptivity lowering performance of low lime fly ash particles was followed by that of high lime fly ash (ECC_H) and ground granulated blast furnace slag particles (ECC_S) in general. When the self-healing rates of pre-loaded specimens are taken into consideration, however, slag particles appear to surpass the performance of high lime fly ash and even low lime fly ash in some cases, when the initial curing period was limited. The self-healing performance of the ECC_S mixtures was surprising since it was presumed that specimens with slag would result in considerably lower amounts of anhydrous materials and higher matrix maturity along with higher total crack openings upon pre-loading. The enhanced self-healing performance of microcracked ECC_S specimens has been of issue in another study of the authors of this paper (Sahmaran et al. 2013). In that study, the authors concluded that since slag particles have lower amounts of $\mathrm{SiO}_{2}$ in their chemical compositions compared to other mineral admixtures, lower rates of pozzolanic reactions are anticipated, which would cause portlandite (as a product of cement hydration) to remain longer and in greater amounts in the cementitious matrices, leading to higher $\mathrm{pH}$ of the pore solution. When the $\mathrm{pH}$ value of pore solution is higher, carbonic acid (a product of the reaction between water and $\mathrm{CO}_{2)}$ can disassociate faster in the forms of bicarbonate $\left(\mathrm{HCO}_{3}{ }^{-}\right)$and carbonate ions $\left(\mathrm{CO}_{3}{ }^{2-}\right)$, which are used for calcite formation by combining with leached-away $\mathrm{Ca}^{2+}$ ions from C-S-H gels 
and portlandite in the presence of $\mathrm{CO}_{2}$ abundant water (Jooss 2001; Edvardsen 1999). Therefore, the increased self-healing capability displayed by the ECC_S specimens was attributed to the calcite formation to a considerable extent. This behavior was also clear during visual observations, since calcite formation manifested itself as white residue inside the microcracks of specimens (Fig. 5).

Generally speaking, self-healing in terms of the sorptivity results became more prominent when the specimens were subjected to pre-loading. In other words, as the microcracks of the specimens increased in number, the tendency for self-healing to take place got higher. However, this behavior was less pronounced in some of the specimens (ECC_H), due most probably to the varying crack characteristics (total crack width, crack length, tortuosity of crack paths etc.) and chemical composition of the mineral admixture, which are decisive for selfhealing performance. A possible explanation for the enhanced self-healing performance monitored in the pre-loaded specimens could be that microcracks are more easily exposed to the ingress of $\mathrm{CO}_{2}$-dissolved water under $\mathrm{CW}$ curing, and they provide additional space for newly-formed self-healing products. However, it should not be forgotten that despite the higher rates of self-healing observed in the pre-loaded specimens, overall sorptivity indexes of highly-damaged specimens after the application of further $\mathrm{CW}$ curing was not as low as in the sound specimens. This is true for all of the specimens presented in this paper. For example, average sorptivity results of 7-day-old sound ECC_L specimens decreased by $49 \%$, becoming $0.0400 \mathrm{~mm} / \mathrm{min}^{1 / 2}$ after only 7 days of $\mathrm{CW}$ curing, while the same results of ECC_L specimens - which had the maximum number of cracks - decreased by $59 \%$, becoming 0.0610 $\mathrm{mm} / \mathrm{min}^{1 / 2}$ after the same further conditioning.

Water movement into conventional concrete through capillary action has been studied extensively by other researchers. In one such study, Neville (1995) concluded that typical sorptivity of normal concrete with a waterto-cement $(\mathrm{W} / \mathrm{C})$ ratio of 0.40 is $0.0900 \mathrm{~mm} / \mathrm{min}^{1 / 2}$. According to other researchers (Tsivilis et al. 2003; Chindaprasirt et al. 2005; Mohammed et al. 2002), concrete with a $\mathrm{W} / \mathrm{C}$ ratio of $0.40-0.50$ shows a sorptivity index of about $0.2300 \mathrm{~mm} / \mathrm{min}^{1 / 2}$. Based on these results from different studies, it can clearly be stated that even the highest sorptivity result $\left(0.0610 \mathrm{~mm} / \mathrm{min}^{1 / 2}\right.$ from 7-day-old ECC_L specimens with the maximum number of cracks) obtained after only 7 days of $\mathrm{CW}$ curing is not specifically high, and it appears that sorptivity values which are lower than the values of solid concrete mixtures are attainable for almost-failed ECC specimens with a limited duration of environmental conditioning.

\subsection{Rapid Chloride Permeability Test (RCPT) 3.2.1 Unhealed specimens}

The rapid chloride permeability test (RCPT) was used in addition to sorptivity measurements as another method to evaluate the self-healing capability of ECCs with different mineral admixtures. RCPT does not, in fact, measure the permeability of concrete. What it does measure is the resistance of concrete to electrical current. However, there is a close relationship between the resistivity of concrete and its permeability. The RCPT results of different ECC mixtures, which offer a good idea about specimens' resistivity against chloride ion ingress, are presented in Table 4. All of the values in this table (a) 7 days
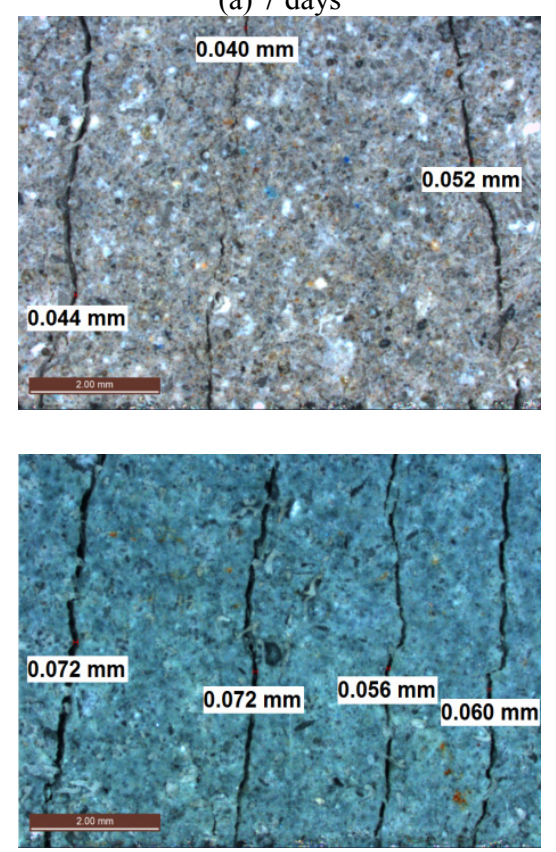

(b) $7+30$ days

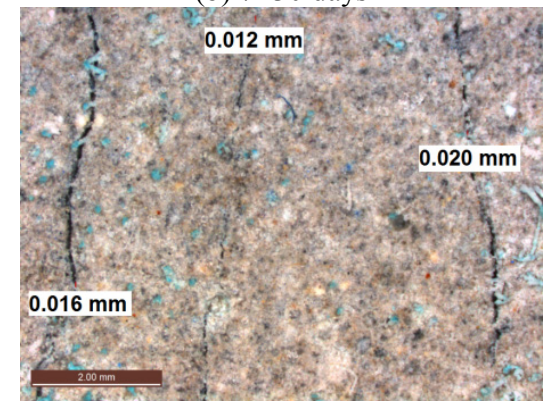

ECC L

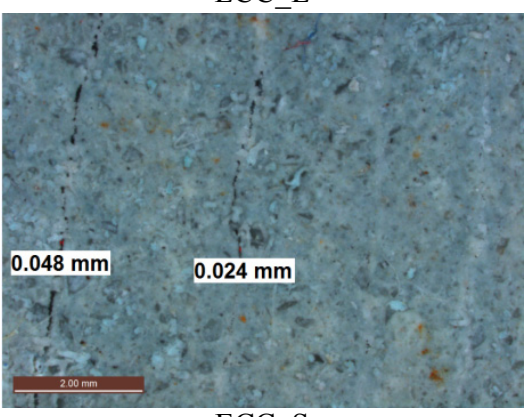

ECC_S (c) 7+90 days
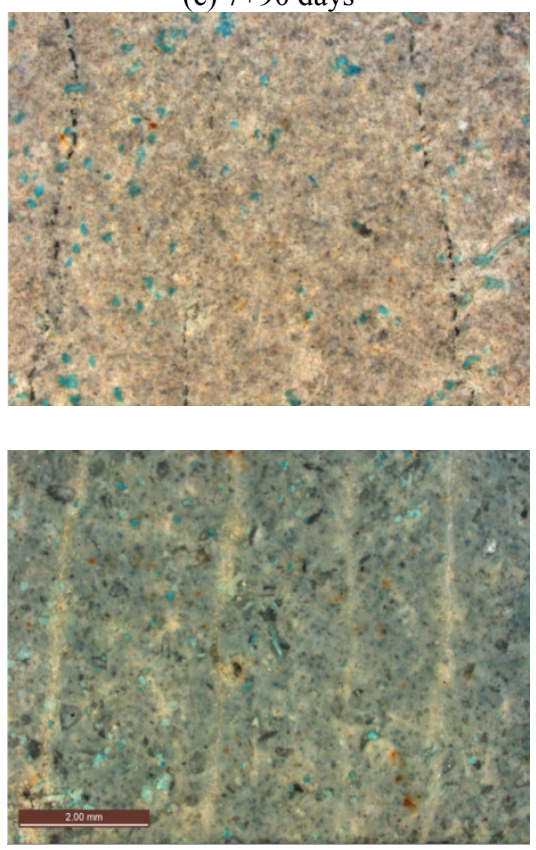

Fig. 5 Typical self-healing of microcracks after exposure to CW curing. 
Table 4 Rapid chloride permeability test results of ECC specimens (units in Coulomb [C]).

\begin{tabular}{|c|c|c|c|c|c|c|c|}
\hline \multirow{2}{*}{ Mix ID. } & \multirow{2}{*}{$\begin{array}{c}\text { Initial } \\
\text { Curing Age }\end{array}$} & \multirow{2}{*}{ Sound } & \multirow{2}{*}{ Pre-loaded } & \multicolumn{4}{|c|}{ Initial Curing + } \\
\hline & & & & 7 days & 30 days & 60 days & 90 days \\
\hline \multirow{3}{*}{$\mathrm{ECC}_{-} \mathrm{L}$} & 7 days & 7169 & 8318 & 5615 & 2475 & 907 & 511 \\
\hline & 28 days & 1615 & 3297 & 2442 & 887 & 577 & 429 \\
\hline & 90 days & 375 & 1308 & 1011 & 478 & 369 & 246 \\
\hline \multirow{3}{*}{ ECC_H } & 7 days & 4863 & 6289 & 3914 & 639 & 405 & 258 \\
\hline & 28 days & 956 & 1654 & 1021 & 517 & 296 & 234 \\
\hline & 90 days & 859 & 1511 & 1186 & 399 & 352 & 330 \\
\hline \multirow{3}{*}{ ECC_S } & 7 days & 6397 & 7888 & 3456 & 1599 & 1305 & 997 \\
\hline & 28 days & 2283 & 3549 & 2654 & 1780 & 1148 & 1007 \\
\hline & 90 days & 1195 & 3686 & 2297 & 1284 & 975 & 909 \\
\hline
\end{tabular}

were calculated by taking the average of three specimens. As seen, results differed significantly, considering different initial curing ages and types of mineral admixtures used. For the RCPT results of 7-day-old sound specimens, results obtained were 7169,4863 and 6397 C for the ECC_L, ECC_H and ECC_S mixtures, respectively. Although the ECC_S specimens were expected to display lower RCPT results, especially during the early stages of hydration, due to the enhanced cementing capability and high specific surface area of slag particles compared to different fly ashes, the results obtained from the ECC_H mixture did not support this assumption. RCPT is an electrochemical test method influenced markedly by the changes in overall porosity of the concrete material and chemical composition of the pore solution. It may therefore be stated that in evaluating RCPT results, great attention must also be paid to the factors governing the chemical state of the pore solution (i.e. calcium silicate hydrate $[\mathrm{C}-\mathrm{S}-\mathrm{H}]$ gels, $\mathrm{CH}$ and alkalis). It is generally accepted that sodium and potassium ions present in cementitious matrices along with either sulfates or hydroxides contribute to the acceleration of early hydration, although they decelerate hydration at later ages (Jawed and Skalny 1978; Juenger and Jennings 2001). Moreover, it has been reported that alkalis are effective in modifying the morphology of calcium silicate hydrate (C-S-H) gels, leading to the formation of lath-like products, which have a higher degree of crystallinity (Mori et al. 1974; Richardson 2004). According to Bentz (2006), the formation of lathlike C-S-H gels in the presence of increased alkali amounts is the reason for the achievement of a depercolated (disconnected) capillary pore network. Despite the enhancements during the early stages of hydration, such microstructural alterations could be responsible for the changes in the transport properties of cementitious systems, which may explain the lower RCPT results obtained from ECC_H specimens with higher concentrations of alkali ions compared to ECC_S. Although it is believed to be less influential, the slightly lower specific gravity of FA-H particles compared to slag, which lead to the higher availability of these particles in the matrices per unit volume, could be another reason for the attainment of more compact systems and lower RCPT results of 7-day-old ECC_H specimens compared to ECC_S.
As expected, prolonging $\mathrm{CW}$ curing resulted in significantly reduced RCPT results due to the continuous development of the cementitious matrices with time. Although the enhancements in RCPT results were close to each other, the results of mixtures incorporating low lime fly ash were generally lower at the end of 90 days. As seen from Table 4, beyond 90 days of initial curing until the end of 90 days of $\mathrm{CW}$ curing, the improvement in chloride ion penetrability of pre-loaded ECC_L specimens was $81 \%$, while the same values were $78 \%$ and $68 \%$ for ECC_H and ECC_S mixtures, respectively. Greater reductions in RCPT results of mixtures incorporating FA-F particles were attributed to higher pozzolanic capacity and the ability of low calcium fly ash particles to remain for a longer period with no chemical interaction in the matrices. Despite the changes in improvements of RCPT results depending on different mineral admixture type, all of the 90-day-old results of sound specimens were in the range of very low chloride ion penetrability levels according to ASTM C 1202, except the ECC_S mixture, which fell in the low range.

With the application of pre-loading, RCPT results increased to a certain level with no regard to initial curing period or mixture type. For instance, the 7-day average RCPT result of the ECC_L mixture increased from 7169 coulomb to 8318 coulomb when specimens were preloaded up to $80 \%$ of their splitting tensile deformation capacities. This behavior was much more pronounced when the specimens were older. When the ECC_S specimens are considered as an example, it is evident that pre-loading caused a $23 \%$ increase in chloride ion penetrability of 7-day-old specimens, although the increase in RCPT results increased to $55 \%$ and $208 \%$ of the initial values in the 28-day-old and 90-day-old specimens, respectively. This behavior could be attributed to the enhanced matrix maturity of the mixtures as a result of the extended curing time, which caused increased matrix fracture toughness values and triggered the formation of localized cracks with wider widths instead of steady-state multiple microcracking (Wang and Li 2007). It must also be stated that the higher percentual increments obtained with the applied preloading were caused due to the fact that calculations were made based on the relatively lower RCPT results obtained at later ages (28 and 90 days). For a better understanding of the application of pre-loading on 
RCPT results, the chloride ion penetrability levels of ECCs (according to ASTM C 1202) before and after cracking can be considered. For example, despite the $55 \%$ increase in average RCPT results of the 28-day-old ECC_S specimens, values stayed in the moderate level before $(2283 \mathrm{C})$ and after (3549 C) pre-loading. This behavior of 28- and 90-day-old specimens was also valid for other mixture types, with slight variations, so that after pre-loading, all RCPT results stayed either in moderate $(<4000 \mathrm{C})$ or low $(<2000 \mathrm{C})$ chloride ion penetrability levels, regardless of mixture type. These observations thus suggest that unlike water permeability (Lepech and Li 2009), the chloride ion permeability of ECC specimens is substantially influenced by the presence of microcracks.

\subsubsection{Effects of self-healing}

Table 4 shows the changes in the RCPT results of ECC specimens pre-loaded up to $80 \%$ of their splitting tensile deformation capacities after 7, 28 and 90 days of initial aging for additional 7, 30, 60 and 90 days of further $\mathrm{CW}$ curing. Percentage changes in chloride ion penetrability results of pre-loaded ECCs subjected to further CW conditioning are provided in Fig. 6. Table 4 and Fig. 6 both clearly show that based on initial curing time, type of mineral admixture and further curing time, selfhealing in terms of the improvements in RCPT results was visible in all mixtures with a minimum level of $20 \%$, which shows the efficacy of $\mathrm{CW}$ conditioning on crack sealing. For all mixture types, whether initially cured for 7, 28 or 90 days, self-healing was much more pronounced after 30 days of $\mathrm{CW}$ conditioning than after just 7 days. However, when a comparison was made between the self-healing rates of ECCs under different transport property testing procedures, sorptivity results dropped drastically after 7 days of CW curing, but only after 30 days of $\mathrm{CW}$ curing for RCPT results. The reason why self-healing rates were lower in terms of sorp- tivity results compared to RCPT results after the first 7 days of CW curing could be due to the completely different natures of the tests. As previously mentioned, RCPT is an electrochemical test significantly affected by a number of parameters. Despite its ease of use, it measures the movement of all ions rather than only chlorides. Voltage applied for ion movement generates heat, which can be substantially high and increase the overall results for less mature specimens. Moreover, the electrical conductance of the concrete is important for RCPT and can be changed drastically by any conducting material (alkalis, free carbon content and so on) which can be present in the pore solution of concrete depending on the maturity of specimens. In the case of sorptivity tests, however, the greater improvements observed especially for younger specimens - could be due to the initial dominance of the connected pores resulting in larger sorptivity values until they are filled, after which disconnected pores dominate with lower sorption effects. Beyond 30 days of $\mathrm{CW}$ curing, self-healing in terms of RCPT results started to lose intensity. For example, for 7-day-old ECC_L specimens, average RCPT results dropped from $8 \overline{3} 18$ to $2475 \mathrm{C}$ level after the first 30 days of CW curing, with slight decrements when curing time was prolonged up to 60 and 90 days; the same results were $907 \mathrm{C}$ and $511 \mathrm{C}$, respectively. The same was true for specimens which were initially cured longer, along with the rest of the mixtures incorporating different mineral admixtures. This trend was not surprising, and was found to be attributable to the availability of more anhydrous materials at early ages and reductions in initial crack volumes at later ages, which may have restricted the visibility of marked self-healing.

Figure 6 shows the percentage reductions in RCPT, indicating that initial curing time was one of the parameters influencing final healing results. Despite the variations in individual healing rates with respect to different mixture types, healing was more obvious for

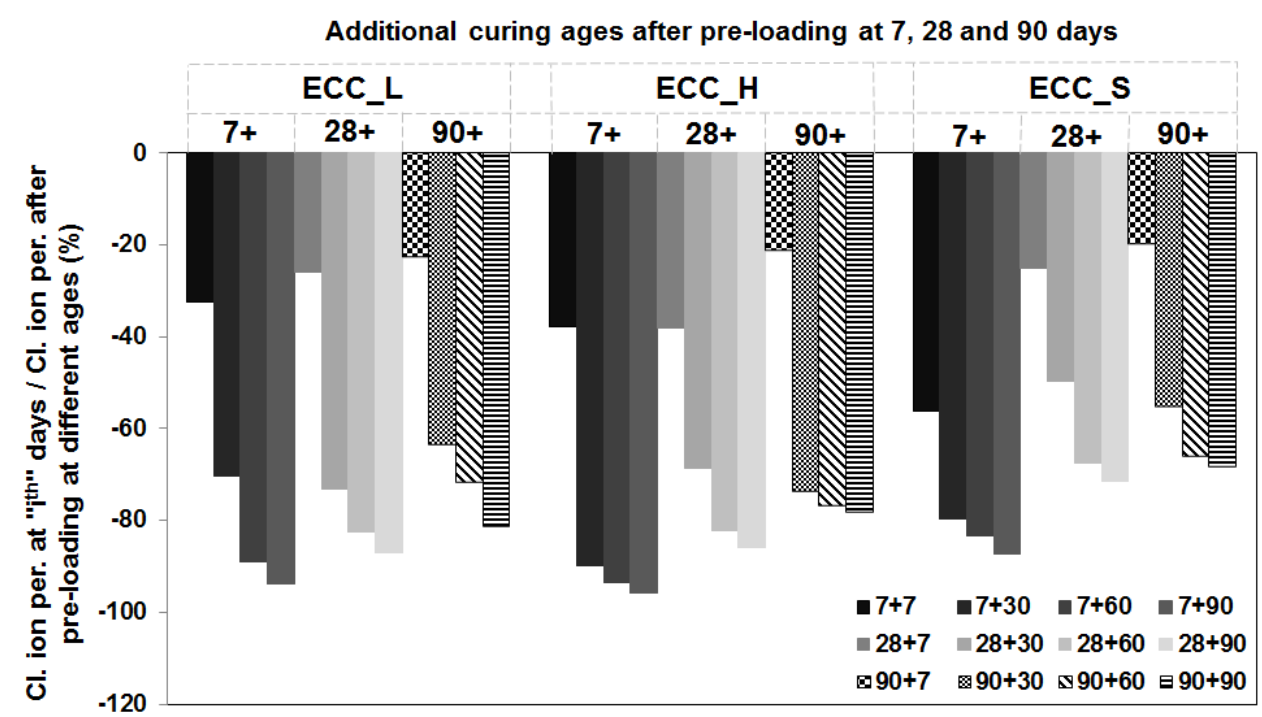

Fig. 6 Percentage changes in chloride ion penetrability results of pre-loaded ECCs with further CW curing. 
specimens cured for 7 days. Contrary to what was expected, specimens that were initially cured for 28 and 90 days did not show noticeable differences in healing rates for all ECCs. For instance, 28-day-old ECC_L specimens that underwent an additional 30 days $\overline{C W}$ curing healed by $73 \%$ of the initial RCPT value after precracking, while the same mixture at 90 days healed by $63 \%$ under the same further curing conditions. It is important to note that this finding could answer the long-standing question of the effectiveness of late-age versus early-age self-healing in cementitious composites. However, further studies, including those examining specimens cured for longer periods, are needed for a complete clarification of this finding.

In regard to the influence of different mineral admixtures on RCPT results of pre-cracked ECC specimens, it can be generally stated that all of the mixtures showed healing rates close to each other, although in some cases ECC_S specimens showed slightly lower results. In a comparison of the self-healing rates of 28-day-old ECC_L and ECC_H specimens with ECC_S specimens after 30 days of $\overline{\mathrm{C} W}$ curing, the results were $73 \%$ and $69 \%$ against $50 \%$ of the initial values after pre-loading, respectively. A similar modality held true for 7- and 90day-old ECC_S specimens subjected to different periods of $\mathrm{CW}$ curing. Possible factors that could be decisive on lower healing rates in terms of the final chloride ion penetrability results of mixtures with slag particles have already been explained. Despite the fact that RCPT results varied significantly based on the chemical composition and initial curing ages of the mixtures, it should be stressed that 30 days of $\mathrm{CW}$ curing is adequate for most of the severely deteriorated ECCs to show low levels of chloride ion penetrability according to ASTM C 1202.

\section{Conclusions}

This paper has presented the evaluation of the selfhealing mechanism in cementitious composites containing mineral admixtures greatly differing in chemical composition. During the analysis, emphasis was placed mainly upon the assessment of the mechanism in terms of sorptivity and RCPT measurements. The following conclusions were drawn:

- The influence of pre-cracking on sorptivity of different ECC mixtures showed exponential increases in values when microcracks were introduced into the specimens. The effect of microcracking on sorptivity appeared to increase its intensity when specimens were cured for longer periods.

- Despite the rapid increases in results with the application of pre-loading, $92 \%$ of healing in the sorptivity measurements was shown to be possible depending on the type of mineral admixture used in the composites, the duration of the initial aging and further CW curing. Contrary to expectations, ECC_S specimens were influential in lowering sorptivity re- sults through self-healing even more than fly-ashbearing ECCs in some cases.

- Chloride ion penetrability results of ECC mixtures increased markedly in the presence of microcracks, although the extent was highly dependent on initial aging and type of mineral admixture used in the mixtures.

- When additional CW curing was applied to the specimens, self-healing realized through improvements in chloride ion penetrability attracted great attention; the RCPT results of most of the almost-failed ECC specimens decreased to low levels according to ASTM C 1202 at 30 days of CW curing.

- When a comparison is made between the healing rates obtained from sorptivity and RCPT measurements, sorptivity results showed sudden drops after only 7 days of $\mathrm{CW}$ curing, while this period was longer (30 days) for RCPT results. The reason for the differences in self-healing performance in the different tests is believed to be due to significantly different testing nature such as high voltage application, temperature changes, high alkalinity of pore solution, capillary effect and so on which have major influences on the individual tests.

\section{Acknowledgements}

The authors gratefully acknowledge the financial assistance of the Scientific and Technical Research Council (TUBITAK) of Turkey provided under Project: MAG112 M876 and the Turkish Academy of Sciences, Young Scientist Award program.

\section{References}

Bentz, D. P., (2006). "Influence of alkalis on porosity percolation in hydrating cement pastes." Cement and Concrete Composites, 28(5), 427-431.

Chindaprasirt, P., Jaturapitakkul, C. and Sinsiri, T., (2005). "Effect of fly ash fineness on compressive strength and pore size of blended cement paste." Cement and Concrete Composites, 27(4), 425-428.

Edvardsen, C., (1999). "Water permeability and autogenous healing of cracks in concrete." ACI Materials Journal, 96(4), 448-455.

Jawed, I. and Skalny, J. P., (1978). "Alkalis in cement: A review II. Effects of alkalis on hydration and performance of Portland cement." Cement and Concrete Research, 8, 37-52.

Jooss, M., (2001). "Leaching of concrete under thermal influence." Otto-Graf-Journal, 12, 51-68.

Juenger, M. C. G. and Jennings, H. M., (2001). "Effects of high alkalinity on cement pastes." ACI Materials Journal, 98(3), 251-255.

Lepech, M. D. and Li, V. C., (2009). "Water permeability of engineered cementitious composites." Cement and Concrete Composites, 31(10), 744-53.

Li, V. C. and Herbert, E., (2012). "Robust self-healing concrete for sustainable infrastructure." Journal of Advanced Concrete Technology, 10(6), 207-218. 
Li, V. C., (1998). "ECC - Tailored composites through micromechanical modeling." Fiber reinforced concrete: present and the future conference. Montreal: CSCE Press, p. 64-97.

Li, V. C., (2003). "On engineered cementitious composites (ECC): a review of the material and its applications." Journal of Advanced Concrete Technology, 1(3), 215-230.

Li, V. C., Wang, S. and Wu, C., (2001). "Tensile strainhardening behavior of PVA-ECC." ACI Materials Journal, 98(6), 483-492.

Martys, N. S. and Ferraris, C. F., (1997). "Capillary transport in mortars and concrete." Cement and Concrete Research, 27(5), 747-760.

Mohammed, T. U., Yamaji, T. and Hamada, H., (2002). "Microstructures and interfaces in concrete after 15 years of exposure in tidal environment." $A C I$ Materials Journal, 99(4), 352-360.

Mori, H., Sudoh, G., Minegishi, K. and Ohta, T., (1974). "Some properties of C-S-H gel formed by $\mathrm{C}_{3} \mathrm{~S}$ hydration in the presence of alkali." $\sigma^{\text {th }}$ International Congress on the Chemistry of Cement, Moscow, p. 212.

Naaman, A. E. and Reinhardt, H. W., (2003). "Setting the stage: toward performance-based classification of FRC composites." High Performance Fiber Reinforced Cement Composites (HPFRCC-4), Published by RILEM S.A.R.L. p. 1-4.

Neville, A. M., (1995) "Properties of concrete." 4th ed. London: Longman Group Limited.

Qian, S., Zhou, J., de Rooij, M. R., Schlangen, E., Ye, G. and van Breugel, K., (2009). "Self-healing behavior of strain hardening cementitious composites incorporating local waste materials." Cement and Concrete Composites, 31(9), 613-621.

Richardson, I. G., (2004). "Tobermorite/jennite- and tobermorite/calcium hydroxide-based models for the structure of C-S-H: Applicability to hardened pastes of tricalcium silicate, $\beta$-dicalcium silicate, Portland cement, and blends of Portland cement with blastfurnace slag, metakaolin, or silica fume." Cement and Concrete Research, 34, 1733-1777.

Romualdi, J. P. and Mandel, J. A., (1964). "Tensile strength of concrete affected by uniformly distributed closely spaced short lengths of wire reinforcement." ACI Journal Proceedings, 61(6), 657-671.

Sahmaran, M. and Li, V. C., (2009). "Influence of microcracking on water absorption and sorptivity of ECC." Materials and Structures, 42(5), 593-603.

Sahmaran, M., Li, M. and Li, V. C., (2007). "Transport Properties of Engineered Cementitious Composites under Chloride Exposure." ACI Materials Journal, 104(6), 604-611.

Sahmaran, M., Yildirim, G. and Erdem, T. K., (2013). "Self-healing capability of cementitious composites incorporating different supplementary cementitious materials." Cement and Concrete Composites, 35(1), 89-101.

Sahmaran, M., Yildirim, G., Ozbay, E., Ahmed, K., and Lachemi, M., (2014). "Self-healing ability of cementitious composites: effect of addition of presoaked expanded perlite." Magazine of Concrete Research, 66(7-8), 409-419.

Tsivilis, S., Tsantilas, J., Kakali, G., Chaniotakis, E. and Sakellariou, A., (2003). "The permeability of portland limestone cement concrete." Cement and Concrete Research, 33(9), 1465-1471.

Wang, S. and Li, V. C., (2007). "Engineered cementitious composites with high-volume fly ash." ACI Materials Journal, 104(3), 233-241.

Wittmann, F. H., (1998). "Separation of assignments: A new approach towards more durable reinforced concrete structures." Proceedings of the Fifth Workshop on Material Properties and Design, Durable Reinforced Concrete Structures, Aedificatio Publishers, 151-160. 